\title{
NAS FISSURAS DA HISTÓRIA: O MOVIMENTO LÉSBICO NO BRASIL
}

Tayane Rogeria Lino'

RESUMO: Este trabalho tem por objetivo realizar uma síntese histórica do Movimento de Mulheres Lésbicas no Brasil (MLB), a partir da segunda metade do século XX, como um requisito da disciplina História e Teoria em Psicologia Social, oferecida no programa de pós-graduação em Psicologia da UFMG. A revisão de literatura sobre o tema aponta que pouco se tem notícia acerca da emergência dos grupos lésbicos no Brasil, as informações aparecem difusas nos estudos sobre a história do Movimento Feminista (MF) e do Movimento Homossexual (MH), o que exige dos/as leitores/as a construção de uma história dentro da exposição da história. Os registros de movimentos organizados de lésbicas são marcados por negociações permeadas de conflitos, debates, encontros e desencontros com os movimentos supracitados. Se a história é o resultado da tentativa de uma interpretação de fatos, uma análise de um momento específico, ela nunca será uma verdade única/singular e sim fragmentos de fatos que produzem redes de sentidos e hierarquias sócio-históricas. Portanto, como aponta Foucault (1979), a história instaura regimes de verdades, nestes termos o que a história não diz nunca existiu. Assim a luta pela construção de uma epistemologia da história das mulheres lésbicas busca o reconhecimento da existência, visibilidade e a inserção na vida pública.

Palavras-chave: Movimento de Mulheres Lésbicas. Participação Política. História. Psicologia Social.

\section{INTRODUÇÃO}

Este trabalho tem como objetivo realizar uma síntese histórica do Movimento Brasileiro de Lésbicas (MBL), a partir de meados da segunda metade do século XX, como parte dos resultados da primeira etapa da pesquisa de mestrado intitulada: A emergência do sujeito coletivo lésbico: uma análise psicossocial do Movimento Lésbico no Brasil.

A referida pesquisa visa investigar a construção das mulheres lésbicas como sujeito coletivo no contexto brasileiro, a partir da constituição da identidade coletiva ${ }^{2}$ do Movimento Brasileiro

1 Psicóloga e Professora de Psicologia de graduação e pós-graduação. Possui graduação pelo Departamento de Psicologia da Faculdade de Filosofia e Ciências Humanas da Universidade Federal de Minas Gerais (UFMG), mestrado e doutora pelo Programa de Pós-Graduação em Psicologia da Universidade Federal de Minas Gerais (UFMG). e-mail: tayanelino@gmail.com.

2 Nesse contexto, faz-se mister enfatizar, que a constituição da identidade coletiva tem um caráter constante, processual, nunca se dando como um fato acabado e finito (Melucci, 2001), sendo ela construída e reconstruída nas 
de Lésbicas (MBL). Nestes termos me interessa compreender como as categorias de gênero e orientação sexual se articulam na cena pública para a constituição de bandeiras de luta e sistemas de ação coletiva, instaurando uma cultura política que é constantemente (re)negociada, (re)construída com o intuito de impensar (Wallerstein, 2006) uma dada realidade social baseada em uma norma heterossexual, sexista, ou, em outras palavras, heterossexista. E, ainda, como o Movimento Feminista e o Movimento LGBT (Lésbicas, Gays, Bissexuais, Transexuais e Travestis) interferem/ contribuem na automização do MBL.

Para tanto, realizo o seguinte percurso: no primeiro tópico abordo a relação entre a Psicologia e o Movimento Brasileiro de Lésbicas, passando para isso nos estudos sobre Movimentos Sociais e a emergência da ABRAPSO; no tópico seguinte apresento a história do Movimento Lésbico na América Latina, principalmente no Brasil, a partir do século XX; e termino com reflexões sobre a produção científica nesta temática.

\section{ESTUDO SOBRO O MOVIMENTO DE MULHERES LÉSBICAS NAS CIÊNCIAS HUMANAS}

Vivemos em um tempo em que a participação da sociedade civil organizada, principalmente o que se convencionou chamar de Movimentos Sociais, tem se feito cada vez mais presente na esfera pública (AVRITZER, 2007; KAUCHAKJE, 2008). Em consonância com este movimento notamos um boom, a partir da segunda metade do século XIX, dos estudos acerca das ações coletivas, movimentos sociais e fenômenos políticos por parte do campo das Ciências Sociais e Humanas no contexto brasileiro (PRADO, 2001; PRADO \& MACHADO, 2005).

Nestes termos afirmamos que a temática dos movimentos sociais não constitui assunto novo (SZTOMPKA, 1998; MELUCCI, 2001; FLACKS, 2005; KAUCHAKJE, 2008; TARROW, 2009). As diversas abordagens presentes sobre os movimentos têm, historicamente, se debruçado na investigação das circunstâncias e fatores que versam em torno da mobilização e/ou a desmobilização social, num esforço para definir e delimitar o que é entendido como Movimento Social diferenciando-o de outras formas de mobilizar-se.

Fruto deste interesse temos visto a construção de um campo teórico e/ou metodológico que visa abarcar a complexidade dos fenômenos coletivos e participativos (MELUCCI, 2001; PRADO, 2001; TARROW, 2009). A história da Psicologia evidencia que esta é uma das áreas que tem se aventurado na investigação e/ou compreensão e politização dos movimentos sociais, principalmente, a subárea da Psicologia Social e Psicologia Política (PRADO, 2000).

No contexto brasileiro é notório o aumento da produção acerca deste tema a partir dos anos $1980^{3}$ com o surgimento da Associação Brasileira de Psicologia Social (ABRAPSO) e, a conse-

ações coletivas, resultado e motivo das ações. A identidade coletiva é definida como o resultado da constituição de um Nós que se constrói em contraposição a um Eles, ou dito de outro modo, a identidade coletiva é a delimitação de fronteiras no que se refere aos direitos sociais, sendo a percepção de um Eles que impede um Nós de realizar suas demandas sociais (Prado, 2002). Assim, nos termos propostos por Prado (2001-2002), a construção da identidade coletiva está baseada no desejo por reconhecimento do princípio de equivalência de direitos na esfera pública e no terreno da diferenciação.

3 Cabe ressaltar que o estudo de fenômenos como "massas", "multidões”, "classes sociais" e "ações coletivas" configurou-se como um lugar expoente no contexto do pensamento das chamadas Ciências Sociais e Humanas, 
qüente 'virada teórica' que esta Associação propõe (BOMFIM, 1989/1990; JACÓ-VILELA, ROCHA;MANCEBO, 2003; CRUZ, 2008). A crise da Psicologia Social na década de 1970 foi uma tensão essencial para mudança de rumo na produção do conhecimento na Psicologia Social brasileira. Em oposição a uma Psicologia Social brasileira que deixava tácito uma ideologia comprometida com a manutenção de uma ordem social desigual e hierárquica, favorecida a classe dominante (LANE, 1984, 1986) viu-se nascer uma área preocupada em explicitar os aspectos ideológicos relacionados à pesquisa em Psicologia Social, empenhada na transformação de uma realidade injusta (CRUZ, 2008).

$\mathrm{Na}$ breve tentativa de um resgate histórico do momento de emergência de Associação, Lane e Bock (2003), discorrem sobre a construção de um conhecimento "que toma posição" socialmente, está politicamente comprometido e engajado na transformação social. A ABRAPSO seria um espaço frutífero para a "construção de uma psicologia social crítica, voltada para problemas nacionais, acatando diferentes correntes epistemológicas, desde que filiadas ao compromisso social de contribuir para a construção de uma sociedade mais justa” (p.149). A transformação proposta passa, entre outras coisas, pela investigação dos Movimentos Sociais.

Cabe aqui ressaltar, que o surgimento da ABRAPSO não resulta no início das investigações dos Movimentos Sociais pela Psicologia. Mas sim, abre possibilidade para o estudo de temáticas ligadas a realidade brasileira - a investigação da construção deste campo do saber com ciência e profissão, os fenômenos participativos, desigualdades de gênero, raça, orientação sexual, classe social, dentre outros.

Cruz (2008) apresenta o aumento na produção que tem como objeto investigativo os Movimentos Sociais em Psicologia Social a partir da década de 1980 o que se mantêm na década seguinte. Já, Perucchi (2009), afirma ter havido, a partir dos anos 90 deste mesmo século, um considerável aumento nos estudos dos movimentos sociais por parte da psicologia. A autora afirma que cabe a Psicologia Social "lançar-se na análise cuidadosa dos vetores de força que caracterizam e constituem os movimentos sociais: a solidariedade, o conflito, a redefinição de seu campo de ação e a produção de efeitos em tal campo" (p.91) realizando análises que remetam a constituição de grupos que implica na "emergência de um "nós" que estabelece os parâmetros de configuração das identidades coletivas" (PERUCCHI, 2009, P.91). Estes dois autores trazem marcos importantes na história da Psicologia se o primeiro tem suas lentes voltadas, principalmente para a crise de 1970 a segunda autora parece sofre a influencia de um momento da tentativa de consolidação da Psicologia Política no Brasil. O que temos, então é a constituição de uma Psicologia Social e uma Psicologia Política que se apresente autônoma aos modelos europeu e americano.

A Psicologia Política na contemporaneidade emerge como um campo de ação/investigação preocupado, "não mais, com uma "psicologização" dos atores coletivos, nem somente com uma "politização" dos fatores psicológicos, mas destinada a compreender os processos articulatórios da criação de identidades coletivas a partir das ações coletivas" (PRADO, 2001, p.170). Afastando-se da dicotomia que, por vezes, se apresenta nos estudos acerca das ações coletivas e dos movimentos sociais que ora têm se debruçado sobre as análises macro-estruturais outrora na investigação dos fenômenos psicológicos da participação (SANDOVAL, 1989; MELUCCI, 2001; PERUCCHI, 2009; TARROW, 2009). Afirmando-se como uma proposta de construção científica que se propõe investigar os aspectos políticos, sócio-históricos e subjetivos da constituição dos fenômenos

desde os fins do século XIX. 
participativas formais e não-formais. Em outras palavras, a mudança oriunda da crise da Psicologia Social instaura a possibilidade do estudo dos fenômenos participativos de forma não neutra e universal, mas um conhecimento local produzido na interação com o outro no meio social, em um contínuo entre sujeito e sociedade.

Nestes termos temos a tentativa de superar as dicotomias históricas entre sujeito e sociedade, coletivo e individual, política e ciência, tem se proposto a compreender os processos psicossociais que circulam a construção das ações coletivas e, consequentemente, das identidades coletivas (PRADO, 2001) - movimentos sociais. Assim como aponta Prado (2001):

(...) a Psicologia Política, ao focar as ações coletivas como objeto de reflexão e compreensão, pode ser entendida como um estudo das condições, sejam elas materiais, simbólicas, institucionais, psicossociais, éticas ou políticas, que são necessárias para a constituição de uma identidade coletiva - NÓS - baseada na diferenciação de um elemento exterior (p.154).

O que se nota, portanto, nas sociedades modernas, que se estabelecem como Estados democráticos de direitos é a constituição de grupos que se reúnem em movimentos sociais na busca de equivalência social e política. Um destes movimentos é o Movimento Lésbico (SELEM, 2007).

Ao contrário do que acontece com o Movimento LGBT e Movimento Feminista a revisão de literatura apontou a ausência de estudos, pesquisas e investigações sobre o movimento Lésbico no Brasil nas Ciências Sociais e Humanas. Em outras palavras acerca da emergência dos grupos lésbicos no Brasil, pouco se tem notícia. As informações aparecem difusas nos estudos sobre a história do Movimento Homossexual e Feminista, o que exige dos/as leitores/as a construção de uma história dentro da exposição da história. Esse árduo exercício explicita o pouco interesse, por parte dos pesquisadores/as por este movimento.

O baixo número de trabalhos, principalmente na Psicologia, além de uma importante constatação, me lançou em uma busca mais ampla sobre a temática. Temas como o Feminismo Lésbico, presente principalmente nas referências Latino-Americanas, a lesbianidade, e o Movimento Homossexual e Feminista se apresentaram como importantes na construção da história do Movimento Lésbico. Ademais, as poucas informações me fizeram percorrer um caminho que incluía produções a partir de estudos empíricos, teóricos e ainda produções de militantes e grupos que constituem o que MBL.

La manera de historiar este movimiento es la de una "arqueología" al estilo foucaultiano. Buscando los rastros de los hechos pasados, los recuerdos de los personajes, los documentos (convertidos en eso a partir de la reciente conformación de archivos), las foto-grafías, las narraciones que por primera vez se estructuraron para tal fin. (MORALES, 2000, p.187)

No que se alude os temas mais investigados pelas Ciências Humanas que tem como eixo transversal a lesbianidade são: saúde da mulher lésbica (ALMEIDA, 2005; MELO, 2010; CALDERARO, 2011), lesbianidade/lesbianismo (MOTT, 1897; LESSA, 2007c; NAVARRO, 19992000); a política e a lesbianidade (MARTINHO, 1989; MESQUITA, 1999; MOGROVEJO, 2000; 
LESSA, 2004-2005-2007-2008; MIÑOSO, 2007; SELEM, 2007); o feminismo lésbico (LESSA, 2007B, CURIEL, 2007); feminismo e lesbianidade (LESSA, 2003; NAVARRO, 2002A; NAVARRO, 2002B; TAVARES, 2011); construção da subjetividade em Movimentos Lésbicos (FERNANDES, 2002), processos identitários (ALMEIDA, 2008; CAMILO, 2010; PIASON; STREY; JULI, 2010).

Foram encontrados apenas três trabalhos que abordassem a lesbianidade na área da Psicologia Social (PIASON; STREY; JULI, 2010; CAMILO, 2010; CALDERARO, 2011) com ênfase em fenômenos participativos. Sendo duas dissertações e um trabalho completo. O primeiro, Mulheres que amam mulheres: trajetórias e vivencias nas militâncias feministas (PIASON; STREY; JULI, 2010), aborda a trajetórias e vivencias nas militâncias feministas se atentando a organização política e a construção identitária. O segundo, Um estudo dialógico sobre narrativas identitárias de mulheres jovens no contexto de coletivos lésbicos-bissexuais feministas (Camilo, 2010), tem ênfase na construção identitária lésbica no interior de um grupo lesbo-feminista. E o ultimo, Políticas de saúde voltadas às lésbicas: um estudo sobre as possibilidades de reverter um quadro histórico de invisibilidade (CAMILO, 2010), acomete a Políticas de saúde voltadas às lésbicas atrelando a luta por direitos e a invisibilidade.

\section{A HISTÓRIA DO MOVIMENTO LÉSBICO}

El lesbianismo feminista para muchas de nosotras no es ni una identidad, ni una orientación, ni una opción sexual; sino una posición política, posición que implica entender La heterosexualidad como un sistema y un régimen político, implica aspirar y construir La libertad y autonomía de las mujeres en todos los planos (Ochy Curiel).

Segundo, Curiel (2007) e Mogrovejo (2000), as primeiras articulações em torno da constituição de um Movimento Lésbico e Homossexual na América Latina e Caribe se deram nos movimentos sociais de esquerda.

La clase social fue la categoría de análisis desde donde se interpretaba la cuestión homosexual (masculina y femenina). Aún en los años sesenta y principios de los setenta no existía la palabra lesbiana, la cual viene a aparecer en 1975 a propósito del Año Internacional de la Mujer, por la influencia feminista (CURIEL, 2007, p.3).

O advento da politização da sexualidade, no século XX, os questionamentos dos discursos que compunham as "tecnologias" de produção do sexo e da normativa heterossexual, instaurada nas sociedades ocidentais, que definiam quem podia ou não falar (Wittig, 1980), fomentou, na década de 70 do século passado, as primeiras articulações e ações de organizações lésbicas na América do Norte (MARTINHO, 1989).

É na segunda onda do feminismo que começamos a ver um questionamento da norma heterossexual (ALVES; PITANGUY, 1991), quando algumas feministas lésbicas, em sua maioria, iniciam uma organização interna. Os debates sobre o pessoal e o político, o corpo, a sexualidade e os direitos sexuais se convertem em bandeiras de luta e passam a ser centrais no fazer política. $\mathrm{O}$ que vemos neste momento é o início da interpelação da universalidade com que as mulheres eram 
tratadas no interior do movimento o que resultava na subordinação e invisibilidade das mulheres lésbicas (COSTA; SOARES 2012; CURIEL, 2007). Ou dito de outro modo "a desconstrução discursiva da "mulher" como categoria unívoca e homogênea" (COSTA; SOARES 2012, p. 3) desencadeou "questionamentos sobre questões que funcionaram como base epistemológica e política do feminismo, nas suas múltiplas interações" (COSTA; SOARES 2012, p. 3). Estas divergências e disputas por significações acarretaram em uma ruptura com o Movimento Feminista.

A pesar de la fuerza política de las lesbianas dentro del feminismo y que muchas de las líderes de esta segunda ola eran lesbianas políticas, el tema del lesbianismo fue un punto de conflicto con las feministas heterosexuales, tensión que llega hasta hoy día. Esto hizo que el separatismo fuese una necesidad para las lesbianas, como una forma de buscar SUS propios intereses feministas y encauzar una práctica y un movimiento con pensamiento y discurso próprio (CURIEL, 2007, p.4).

O chamado "movimento separatista" questionava a heterossexual compulsória que incidia sobre os corpos femininos e que o Movimento Feminista radical não conseguia capturar (SELEM, 2007) por um misto de motivos, entre eles o "medo" das feministas de serem associadas às homossexualidades (TAVARES, 2011). O que resultou, no que as feministas lésbicas nomearam como hierarquização das bandeiras políticas deste movimento, afirmando que as questões ligadas especificamente às lesbianidades, nunca eram postas na ordem do dia, em termos de reivindicações de direitos. Esta conjuntura tem como fim a busca por um espaço exclusivo de mulheres lésbicas e a construção de pautas que atendiam as especificidades estas.

A década de oitenta do século passado é marcada por importantes encontros feministas que culminam na criação de novos coletivos (CURIEL, 2007). No I Encontro Feminista Latino americano e do Caribe realizado na Colômbia no ano de 1981 nasce o grupo peruano Grupo de Autoconsciência de Lesbianas Feministas (GALF), Ayuquelén en Chile. Dois anos dois no segundo encontro, realizado en Perú nascem Las Entendidas da Costa Rica, Mulas do México, Mitilene da República Dominicana, GALF no Brasil e muito outros em toda a America Latina (CURIEL, 2007).

Na década de noventa, segundo Curiel (2007), outros grupos aparecem com força política, grupos lesbico-feministas ganham espaços, redes e articulações nacionais surgem e, principalmente grupos composto exclusivamente por lésbicas crescem, o que, também, acontece no Brasil, como veremos a seguir.

Neste mesmo período histórico as primeiras organizações homossexuais mistas nascem nos Estados Unidos, sobre a influência dos dias de mobilização no Bar Stonewall em 1969, quando gays, lésbicas, travestis cansados da repressão policial da cidade de New Yorque tomam as ruas e começam embates físicos. O que motiva um ano mais tarde uma marcha, com mais de dez mil participantes, e a organização de grupos pro direitos LGBT. A partir de então, o dia 28 de junho foi nomeado como dia do Orgulho Gay. Neste dia, os homossexuais afirmam sua história de resistência e combate à homofobia em todo o Ocidente.

As manifestações de Stonewall foram sentidas, também, na América Latina e transformaram "ruídos em barulhos" dando origem a grupos homossexuais mistos. Cabe ressaltar a presença de mulheres lésbicas e bissexuais. Fruto de desencontros com militantes e perspectivas machistas no interior do movimento LGBT vê-se a repetição da impossibilidade de diálogo no Movimento 
Homossexual assim como no Movimento Feminista. As lésbicas presentes passam a se perceber em um sistema desigual baseado em uma normativa do gênero, submetidas a um sistema sexista onde as pautas lésbicas eram tratadas como inferiores e as mulheres como auxiliares da ação localizando-as atrás das cortinas da luta o que acarreta em uma ruptura e no nascimento de grupos lésbicos.

$\mathrm{Na}$ conjuntura brasileira as primeiras organizações LGBT (Lésbicas, gays, bissexuais, travestis e transexuais), emergem na década de 1970, mas apenas após desencontros políticos no grupo SOMOS (MARTINHO, 1989). Quando as lésbicas, predominantemente feministas, começam a requerer maior presença e visibilidade no primeiro grupo de afirmação homossexual (MESQUITA, 2004). Nos anos oitenta, surge o primeiro grupo lésbico denominado Grupo Lésbico-Feminista (LF) em São Paulo, posteriormente rebatizado de Grupo de Ação Lésbico-Feminista (GALF) (PIASON; STREY; JULIO, 2010). E logo em seguida o Lamuricumá no Rio de janeiro, que se desfaz rapidamente (FACCHINI, 2003) ${ }^{4}$.

Facchini (2003) afirma que, após a ruptura com o SOMOS, o LF voltou-se para o Movimento Feminista, com o intuito de construir espaços dentro deste movimento que resultassem em mais atenção as questões ligadas à sexualidade. Após a participação no II Encontro Feminista Latino americano e do Caribe e conflitos internos o grupo muda de nome Grupo de Ação LésbicoFeministas (GALF). O GALF se re-configurou algumas vezes mudando inclusive de nome: Grupo Terra Maria, Rede de Informação Um Outro Olhar ${ }^{5}$. Este grupo passa a negociar ora com o Movimento Feminista ora com o Movimento LGBT, negociações estas que resultavam em aproximações e rupturas.

O mesmo movimento de aproximação e distanciamento do Movimento Feminista e Homossexual é notado em outros grupos lésbicos da época (MARTINHO, 1989; MESQUITA, 2004; FACCHINI, 2005-2009; FACCHINI; SIMÕES, 2009; PIASON, STREY; JULIO, 2010), o que acaba por caracterizar, em larga medida, o Movimento Lésbico.

De maneira geral os grupos feministas resistiram a incorporar as questões das mulheres lésbicas, tanto em sua produção teórica como na sua agenda política. (FERNANDES, 2002; MESQUITA, 2004; COSTA; SOARES 2012). De acordo com Marisa Fernandes (2002), boa parte das tensões advém do silêncio do feminismo perante as violências sofridas pelas lésbicas, como o chamado estupro corretivo. Por essa razão, "também para as lésbicas brasileiras, o espaço de definição estratégico passa a ser os Encontros lésbicos latino-americanos e do Caribe" (COSTA; SOARES 2012, p.13). Sendo um espaço de resistência e acolhimento de militantes lésbicas, no qual são delineadas estratégias políticas que privilegiavam outras linguagens, as artes, momentos de conversa e interação a fim de compensar a insuficiência dos recursos políticos tradicionais (COSTA; SOARES, 2012).

O advento da tecnologia (ALMEIDA, 2008) e os encontros nacionais feministas (COSTA; SOARES, 2012), que tiveram seu auge na década de 80 e 90, foram momentos importantes de

4 É importante enfatizar uma diferença marcante na emergência de grupos lésbicos no Brasil. Se nos países da America Latina estes grupos estão muito vinculados ao Movimento Feminista no Brasil o movimento se dá a partir do Movimento LGBT.

5 Assim como em outros movimentos sociais a organização lésbica vivencia em seu cotidiano convergências e divergências, fruto por um lado de perspectivas políticas que se tornam incompatíveis, e por outro de atritos pessoais e/ou afetivos/sexuais que (im)possibilitam o convívio coletivo. Quando estas divergências se tornam extremadas vê-se a necessidade de redefinições (Mesquita, 2004). 
visibilização da presença lésbica no feminismo para feministas. Ainda que a lesbianidade não fosse, em nenhum momento, colocada na pautada no temário central, as mulheres lésbicas se organizavam para a realização de espaços paralelos: oficinas, reuniões, promoviam visibilidade nas festas, demarcando sua existência e presença nos encontros, sem pedir licença para entrar (COSTA; SOARES, 2012).

De acordo com Miñoso (2007), no que se refere ao Movimento Homossexual, as mulheres lésbicas e organizações lésbicas percebem o espaço misto como inviável de empreender uma luta política lésbica e feminista. Estas acreditavam que o Movimento Homossexual havia abando uma postura mais radical em prol de um discurso que enfatiza a diversidade, o que o empobrecido politicamente, especialmente, por não questionar a heterossexualidade obrigatória.

Se a década de 1980 é fortemente marcada por uma presença ainda insipiente de grupos lésbicos, a década seguinte marca a emergência de organizações do segmento e a ocupação do cenário brasileiro de forma menos isolada: há a criação de grupos compostos exclusivamente de lésbicas, o fortalecimento de núcleos e segmentos lésbicos em grupos mistos e, ainda, o aparecimento de ativistas independentes que militam em fóruns, redes e articulações, fazendo com que, no contexto brasileiro, os grupos de lésbicas se multipliquem e conquistem maior visibilidade.

No bojo dessas rupturas e emergências na luta pela emancipação social, econômica, sexual e cultural das lésbicas é criado, na segunda metade da década de noventa, o SENALE - Seminário Nacional de Lésbicas que reúne, a cada dois anos, organizações que defendem as causas lésbicas e bissexuais que compõe o ML.

O SENALE surge no ano de 1996 a partir da constatação da ausência de espaços específicos para discussão de questões ligadas às sexualidades femininas e, principalmente, as questões da vivência das homossexualidades femininas e a percepção de que espaços mistos não se mostravam suficientes para os anseios políticos destes grupos. Outro ponto crucial para a construção do seminário foi à necessidade de criar espaços de diálogo, interlocução e trocas para a construção de pautas e bandeiras comuns entre os diversos grupos que compunham o ML (PIASON; STREY; JULIO, 2010).

Este evento torna-se, a partir de então, o maior fórum político exclusivamente lésbico do país. Cabe enunciar que o movimento de lésbicas não se esgota nos sujeitos políticos participantes dos Senales. Os Senales são estruturados por representantes de algumas ONGs lésbicas, algumas poucas lésbicas oriundas de partidos políticos e ainda por outras que se consideram lésbicas ou bissexuais "independentes", por não atuarem na condição de integrantes/representantes institucionais (ALMEIDA, 2008, p. 229).

O SENALE atua hoje no fomento e fortalecimento de organizações voltadas para o segmento lésbico no Brasil a partir do debate de temas de interesse como sexualidade, saúde, gênero, combate à violência, diversidade, política, entre outros. Tem também nos momentos preparatórios e no encontro, propriamente dito, o momento de construção de bandeiras políticas, demandas sociais, formas de ação nas distintas regiões do país, diretrizes para políticas públicas e para as diferentes expressões do movimento. Foi ainda um campo frutífero para a organização da I Caminhada de Mulheres Lésbicas, Bissexuais, aconteceu em 2003 em referencia ao dia 29 de Agosto como Dia Nacional da Visibilidade Lésbica para todas as regiões do Pais.

O percurso político do Movimento de Lésbicas, propiciado pelos diversos espaços de interlocução dos últimos anos - debates, grupos de reflexão, seminários, encontros, atividades culturais, ações de rua como caminhadas, as Paradas do Orgulho LGBT - e as interpelações públicas, contribuíram 
significativamente para o movimento atual, a formação de redes e articulações nacionais que visam à apresentação do Movimento de Lésbicas. Estas, supostamente, apresentariam ao mundo externo como um todo sólido. Sendo instâncias de empoderamento e mobilização nacional e internacional das lésbicas criada por mulheres que ousaram politizar a sexualidade, e tratar a lesbianidade como identidade política (Mesquita, 2004).

Mas o que temos visto é que o "lesbianismo político" (ALMEIDA, 2008) brasileiro contemporâneo, de forma geral, tem se articulado em torno de três grandes entidades agregadoras nacionais, como a LBL (Liga Brasileira de Lésbicas), ABGLT (Associação Brasileira de Gays, Lésbicas e Transgêneros) e a ABL (Articulação Brasileira de Lésbicas). Duas exclusivamente compostas por grupos lésbicos e bissexuais e uma mista, havendo posições francamente favoráveis à articulação com os outros integrantes da sopa de letrinhas (LGBT) (FACCHINI, 2005) e justificam o apoio pela potencialização da ação política, e outro grupo de lésbicas que consideram prejudicial à autonomia do movimento. "Estas entidades, por sua vez, divergem por diferentes motivos: desde disputas de poder e de espaço de re-presentação governamental entre lideranças, até desavenças quanto à demarcação de fronteiras identitárias" (ALMEIDA, 2008, p.229).

$\mathrm{Na}$ atualidade, o que podemos dizer é que as reivindicações versam em trono de maior visibilidade, instauração de políticas públicas, na busca pelo respeito, dignidade e cidadania. As chamadas Caminhas Lésbicas são um importante momento de apresentação pública e de questionamento público/político.

\section{CONSIDERAÇÕES FINAIS}

A revisão explicitou que pouco se tem notícia acerca da emergência dos grupos lésbicos no Brasil, as informações aparecem difusas nos estudos sobre a história do MH e do MF, o que exige dos/as leitores/as a construção de uma história dentro da exposição da história. Se a história é o resultado da tentativa de uma interpretação de fatos, uma analise de um momento específico, a história nunca é uma verdade única e singular e sim fragmentos de fatos que servem e produzem redes de sentidos e hierarquias. A história, como bem aponta Foucault (1979), instaura regimes de verdades, nestes termos o que a história não diz nunca existiu. Assim a luta pela construção de uma epistemologia da história das mulheres lésbicas, nada mais é, do que a busca pela existência, visibilidade e aquisição de direitos.

A constituição do reconhecimento da identidade lésbica é mais que uma preferência sexual, um desejo, é uma opção política porque desafia o sistema político heteronormativo estabelecido na sociedade vigente que obriga que as relações entre homens e mulheres sejam relações de poder e que, por vezes são reconhecidas como de domínio e opressão (MOGROVEJO, 2000).

Os registros de movimentos organizados de lésbicas são marcados por negociações permeadas de conflitos, debates, encontros e desencontros com o Movimento Homossexual (MH) e o Movimento Feminista (MF). As análises preliminares apontam que aproximações e rupturas com o Movimento Feminista e Homossexual é marcante ao longo da constituição do Movimento Lésbico no Ocidente. Hoje, os conflitos ainda se fazem presentes, mas estes movimentos já não parecem ser o "outro", o adversário na constituição de um nós. As teóricas feministas que acreditam que a associação entre feministas e lésbicas cumpre a função política e pedagógica de alertar as mulheres ao sistema heteronormativo e hierárquico a que estão submetidas (COSTA; SOARES 2002; CUREIL, 2007). 
Assim podemos apontar que o Movimento Lésbico se constitui na transversalidade das agendas do Movimento Feminista e do Movimento LGBT (CAMILO, 2010). Visa, a partir da delimitação do campo de especificidades e articulações em torno das categorias de gênero e orientação sexual, visibilizar as questões das lésbicas enquanto sujeito coletivo que leva consigo uma identidade abalizada por relações de opressão, preconceito e subordinação específicas, ocasionadas pelo sexismo e lesbofobia.

\section{REFERÊNCIAS}

ALMEIDA, Glaucia Elaine da S. Da invisibilidade à vulnerabilidade: percursos do "corpo lésbico" na cena brasileira face à possibilidade da infecção por DST e AIDS. Tese (Doutorado em Saúde Coletiva) Instituto de Medicina Social, Universidade Estadual do Rio de Janeiro: Rio de Janeiro, 2005.

ALVES, Branca Moreira; PITANGUY, Jaqueline. O que é feminismo. 8. ed. São Paulo: Brasiliense, 1991.

AVRITZER, Leonardo. Sociedade Civil, Instituições Participativas e Representação: Da Autorização à Legitimidade da Ação. DADOS - Revista de Ciências Sociais, v. (50) n.(3), Rio de Janeiro, 2007.

BOMFIM, Elizabeth M. A Psicologia Social da ABRAPSO. Psicologia e Sociedade, v.(8), p. 219-225, $1989 / 1990$.

CALDERARO, Fernanda. Políticas de saúde voltadas às lésbicas: um estudo sobre as possibilidades de reverter um quadro histórico de invisibilidade. (Dissertação de mestrado). Pontifícia Universidade Católica de São Paulo, 2011.

CAMILO, A. A. Um estudo dialógico sobre narrativas identitárias de mulheres jovens no contexto de coletivos lésbicos-bissexuais feministas. (Dissertação de Mestrado) - Instituto de Psicologia, Universidade de Brasília, 2010.

CRUZ, R. N. Da. A produção social do conhecimento na Psicologia Social brasileira: um estudo descritivo/ exploratório a partir da revista Psicologia \& Sociedade. Dissertação de Mestrado, Programa de PósGraduação em Psicologia. Universidade Federal de Minas Gerais, 2008.

CURIEL, Ochy. El lesbianismo feminista: Una propuesta política transformadora. Revista America Latina em Movimento, n. 420, P. 3-7, 2007. Disponível em: http://alainet.org/active/show_text.php3?key=17389. Acesso em 02 de outubro de 2019.

FACCHINI, Regina. Sopa de letrinhas? Movimento homossexual e produção de identidades coletivas nos anos 90. Rio de Janeiro: Garamond, 2005.

FACCHINI, Regina. Entre compassos e descompassos: um olhar para o "campo" e para a "arena" do movimento LGBT brasileiro. Revista Bagoas, 2009.

FERNANDES, Marisa. Lésbicas no Brasil, 2002. Disponível no site: http://gonline.uol.com.br/entre_elas/filosofando/filosofando.shtml. Acesso em 30 de maio de 2019.

FLACKS, D. A questão da relevância nos estudos dos movimentos sociais. Revista Crítica de Ciências Sociais, 72, p. 45-66, 2005. 
FOUCAULT, M. Microfísica do poder. Rio de Janeiro: Graal, 1979.

JACÓ-VILELA, A. M.; ROCHA, M.L.; Mancebo, D. (Orgs.). Psicologia Social: relatos na América Latina. São Paulo, SP: Casa do Psicólogo, 2003.

KAUCHAKJE, Samira. Solidariedade política e constituição de sujeitos: a atualidade dos movimentos sociais. Sociedade e Estado, Brasília, v. (23) n. (3), p. 667-696, 2008.

LANE, Silvia T.M. (1984). O que é psicologia social. In S. LANE; W. CODO (Eds.), Psicologia social O homem em movimento. São Paulo, SP: Brasiliense, 1984.

LANE, Silva T.M.A Psicologia Social e uma nova concepção de para a Psicologia. In: S. LANE; W. CODO (orgs.). Psicologia Social: o homem em movimento. São Paulo: Brasiliense, 1984.

LANE, S. T. M.; BOCK, A. M. B. ABRAPSO - uma história da Psicologia Social enquanto práxis. In: JACÓ-VILELA, A. M.; Rocha, M. L;MANCEBO, D. (Orgs.) Psicologia Social: relatos na América Latina. São Paulo: Casa do Psicólogo, p. 145-155, 2003.

LESSA, P. O que a história não diz não existiu: a lesbianidade em suas interfaces com o feminismo e a historia das mulheres. Em Tempo de Histórias, v. (7), 120-132, 2003.

LESSA, P. A lesbianidade em fotos e cores In: Anais do XXIII Simpósio Nacional de Educação Física e II Colóquio de Epistemologia do CBCE. Pelotas: EDUFPEL, 2004.

LESSA, P. Lesbianas em movimento: a criação de subjetividades (Brasil, 1979-2006). Tese (Doutorado em História) - Universidade de Brasília, Brasília, 2007.

LESSA, P. O feminismo-lesbiano em Monique Wittig. Revista Ártemis, v. (7), p. 93-100, 2007b.

LESSA, P. O que é o lesbianismo. Em Tempo de Histórias, v. (9), 150-153, 2007c.

LESSA, P. Visibilidade e ação lesbiana na década de 1980: uma análise a partir de grupo de ação lésbico-feminista e do boletim Chana com Chana. Gênero, v. (8), 301-334, 2008.

LESSA, Patrícia A construção dos corpos lesbianos nos movimentos sociais no Brasil frente os anos 70 e a atualidade. In: Anais do XXIII Simpósio Nacional de História - ANPUH e História: Guerra e Paz. Londrina: EDUEL, p. 379-379, 2005.

MARTINHO, Míriam. Lésbicas em Movimento: a trajetória da organização lésbica no Brasil. Boletim Um Outro Olhar, n. 9, 1989. Disponível em www.umoutroolhar.com.br. Acesso em 15 de março de 2019.

MELO, A. P. L de. "Mulher Mulher" e "Outras Mulheres": gênero e homossexualidade(s) no Programa de Saúde da Família. (Dissertação de Mestrado) - Universidade do Estado do Rio de Janeiro, Instituto de Medicina Social, 2010.

MELUCCI, A. A invenção do presente. Petrópolis, Editora Vozes, 2001. 
MESQUITA, M. Movimento de mulheres lésbicas no Brasil: sinalizando algumas conquistas e desafios para o século XX, 2004. Disponível em: www.galf.org. Acesso em 15 de março de 2019.

MIÑ̃SO, Yuderkys Espinosa.. Escritos de una lesbiana oscura: reflexiones críticas sobre feminismo y política de identidade en America Latina. Buenos Aires: Frontera, 2007.

MOGROVEJO, Norma. Um amor que se atrevo a decir su nombre - La lucha de las lesbianas y su relación con los movimientos homosexual y feminista en América Latina. México: Plaza y Valdés, 2000.

MORALES, Zeyda Rodríguez. El movimiento lésbico en México: reconstrucción de uma historia no escrita. Espiral, Estudios sobre Estado y Sociedad. V. (7) n. (19), p.187-192, 2000.

MOTT, Luiz O lesbianismo no Brasil. Porto Alegre: Mercado Aberto, 1987.

NAVARRO-SWAIN, T. Feminismo e lesbianismo: a identidade em questão. Cadernos Pagu (UNICAMP), Campinas, São Paulo, v. (12), p. 109-120, 1999.

NAVARRO-SWAIN, T. Feminismo e lesbianismo: quais os desafios?. Labrys. Estudos Feministas (Edição em português. Online), 2002a.

NAVARRO-SWAIN, T. Feminismo e práticas sexuais. Caderno Espaço Feminino (UFU), v. (9) n. (10/11), p. 09-34, 2002b.

NAVARRO-SWAIN, T. Lesbainismo: identidade ou opção individual?. In: PEDRO, Joana Maria et al. (Org.). (v. 2, p. 1223-1241). História: fronteiras. Florianópolis: FINEP, 1999.

NAVARRO-SWAIN, T. O que é o lesbianismo. São Paulo: Brasiliense, 2000.

PRADO, M. A. M. Psicologia Política e Ação Coletiva: notas e reflexões acerca da compreensão do processo de formação identitária do "nós". Psicologia Política, 1(1) p. 173-195, 2000.

PRADO, M. A. M. Psicologia política e ação coletiva. Revista Psicologia Política, 1(1), 149-170, 2001.

PRADO M. A. M; MACHADO, F. V. Movimentos Homossexuais: A Constituição da Identidade Coletiva Entre a Economia e a Cultura: O Caso de Dois Grupos Brasileiros. Interações, 10(19), p. 35-62, 2005.

PIASON, Aline da Silva; STREY, Marlene Neves; JULIO, Ana Luiza dos Santos. Mulheres que amam mulheres: trajetórias e vivencias nas militâncias feministas. Anais do Fazendo Gênero 9: Diásporas, Diversidades, Deslocamentos. P.1-8, 2010.

SANDOVAL, S. A. M. A crise sociológica e a contribuição da psicologia social ao estudo dos movimentos sociais. Educaşão e Sociedade, 2(34), 122-130, 1989.

SELEM, Maria Célia Orlato. A Liga Brasileira de Lésbicas: produção de sentidos na construção do sujeito político lésbica. Dissertação (Mestrado em História) - Universidade de Brasília, 2007.

SIMÕES, Júlio Assis; Facchini, Regina. Na trilha do arco-íris: do movimento homossexual ao LGBT. São Paulo, Perseu Abramo, 2009. 
SOARES, Gilberta Santos; Costa, Jussara Carneiro. Movimento lésbico e Movimento feminista no Brasil: recuperando encontros e desencontros. labrys, études féministes/ estudos feministas, 2012.

SZTOMPKA, P. A sociologia da mudança social. Rio de Janeiro, Civilização Brasileira, 1998.

TARROW, S. O Poder em Movimento: Movimentos sociais e confronto político. Editora Vozes, 2009.

TAVARES, M. Lesbianismos e feminismos encontros e desencontros e as ligações entre activismo e academia. LES Online, v. (3) n. (1), 29-37, 2011.

WALLERSTEIN, Immanuel. Impensar a Ciência Social: Os limites dos paradigmas do século XIX. Aparecida: Idéias \& Letras, 2006. 